\title{
Deap-Malmquist Productivity Index in China and Its Decomposition During 1985-2008
}

\author{
Yuhua Yang \\ School of Marxist \\ Henan University of Science and Technology Henan \\ Luoyang, China, 471003 \\ E-mail: yangyh@haust.edu.cn
}

\author{
Rui Qin \\ School of Marxist \\ Henan University of Science and Technology Henan \\ Luoyang, China, 471003
}

\begin{abstract}
Based on Deap-Malmquist index during 19852008, the empirical analysis shows that: total factor productivity growth improve by period in China. Our economic growth mode transfer steady, but not balanced. Among them, the east and northeast China as a whole technology progress faster, efficiency improve obviously, economic growth mode transformation walk in the front in the whole country. The western region is basically synchronous with the national, efficiency improved clearly, and technological progress is slow; the central region technology stagnation, inefficiency, the change of the economic growth mode is seriously lagging behind. Technical progress is first force to promote the economic restructuring, pure technical efficiency contribution to the second, and the influence of international economy environment is larger too. So, it is necessary to increase investment in science and technology innovation, to vigorously develop modern service industry, to expand domestic demand, coordinating regional development, maintain a steady improvement in productivity, and promote economic growth mode transformation.
\end{abstract}

Keywords-economic growth mode restructuring; TFP; technological progress; Malmquist Index

\section{INTRODUCTION}

Since the reform and opening, our country's economy is developing with more than 30 years of growth, the average annual GDP growth at $9.95 \%$. But with the increasing restriction of the resources and environment, the quality and efficiency of economic growth has become the main factor to restrict the sustainable development of China's economy. Many experts and scholars think, China's economic growth mode is inputs-led growth with a high investment and low efficiency. Therefore, the purpose of this study is comprehensive analyze and judg the trend of economic growth in China and its motive structure change, and objective evaluate the trend to transformate the mode of economic growth in China. This paper use data envelope analysis method to study the inter-provincial empirical data from 1978 to 2008 for productivity, compare with interprovincial, regional economic growth structure, reading between the inter-provincial productivity gains and their

Fund project: Social sciences planning project in henan province: A study on the China's foreign trade strategy transformation and its path by Comparing Marx and western trade theories (Project No.2015BJJ080 );

Humanities and social science research innovation ability fund of Henan university of science and technology (Project No. 2013 WCX006). difference of productivity decomposition, and judge the economic growth style in province area and its quality and benefits.

On the methods of study on the factors of economic growth and growth mode, the domestic scholars mainly have three ideas: First, study on the factors of economic growth and its assessment replaced technology progress with total factor productivity. Such as Fleisher and Chen (1997) use economic growth accounting method researched TFP changes of 25 provinces in China from 1978 to 1993 [2] Ye Yu min (2002) [3] Guo Qingwang, Jia Junxue (2005) [4] Zheng Jinghai, Hu Angang (2005) [5] People such as based on economic growth accounting model and measuring TFP of the national and provincial. Secondly, the use of the econometric method based on general production function to analyze on TFP and its decomposition. Zhang Jun and Shi Shaohua (2003) using regression analysis on the China's economic statistics data, to estimates the TFP of Chinese economy [6]. The world bank (1998) decomposed the source of economic growth into capital accumulation, job growth, human capital growth and TFP growth [5]. Third, using the stochastic frontier analysis (SFA), data envelopment analysis (DEA) to study TFP and its decomposition. Cowgill

(2001) using the stochastic frontier model to study TFP for 13-year data of 28 provinces in China [7]; Yan Pengfei, Wang Bing(2004) used DEA method to measure the Chinese inter-province technical efficiency, technical progress and Malmquist index[8]. Jin Xiangyu (2006), reserched TFP of the regional economic growth in China and divided the TFP into efficiency changes, technical change, pure technical change and scale efficiency changes with using DEA method[9]. Gao Chunliang (2007) reserched economic growth of 216 cities in China and measure their efficiency with DEA-Malmquist index[10].

In the progress of the comparative study of China's provincial productivity, because the difference of the analysis, accounting methods and the different sample selection, leading to the conclusion of the differences. Guo Qingwang, Jia Junxue (2005) think we should "optimize the allocation of resources and enhance the technical efficiency", And Yanpengfei, Wang bing (2004) emphasize the importance of technology progress. This study will give a Deap -Malmquist Productivity Index among the 32 provinces 
in China during 1985-2008 by using the efficiency and productivity analysis center's data envelopment analysis software DEAP2.1 from the University of Queensland in Australia, And comparative analysis among them to draw a more representative conclusion.

\section{MALMQUIST INDEX METHOD AND DATA COLLECTION AND PROCESSING}

\section{A. Malmquist Index Method}

In 1953, Swedish economist Sten Malmquit has been proposed the concept of scaling factor in the analysis of production. He built consumption index make use of the ratio between the scaling factors, and this had created the first Malmquist index. Since then, the Caves applied the Malmquist consumption index to analyze the production index in 1982, "construction productivity index by the ratio of the distance function ", and the index name Malmquist productivity index [10], because it was lack of distance functions of the measurement method, so at that time, Malmquist index is only a theoretical index and people failed to pay too much attention it.

In 1978, Charnes, Cooerh and Rhodes presented the data envelopment analysis (DEA) by using linear programming to measure the efficiency of technology. DEA can Statistics and analysis the availability of the "decision unit" (DMU) through the mathematical programming model with multiple input and output data. It is because of the DEA method make up for the lack of Malmquist index to measure effectively, Malmquist index also began to gradually into the empirical analysis period. It is also based on the DEA method, Fare etc. (1994) Further, decomposed Malmquist index into four indicators: efficiency improvement, technical change, pure technical efficiency and scale efficiency.

\section{1) DEA-Malmquist Index Model}

By using the DEA method, we can express theTFP change of Malmquist index in a certain period of time through the following formulas.

First of all, set M0 (qs, xs; qt, $\mathrm{xt}$ ) for sample in, $\mathrm{S}$ to $\mathrm{T}$ as a unit period for total factor productivity change of markov index. Then :

$$
\begin{aligned}
& M_{0}\left(q_{s}, x_{s} ; q_{t}, x_{t}\right)=\sqrt{\frac{d_{0}^{s}\left(q_{t}, x_{t}\right)}{d_{0}^{s}\left(q_{s}, x_{s}\right)}} \sqrt{\frac{d_{0}^{t}\left(q_{t}, x_{t}\right)}{d_{0}^{t}\left(q_{s}, x_{s}\right)}} \\
& M_{0}\left(q_{s}, x_{s} ; q_{t}, x_{t}\right)=\frac{d_{0}^{t}\left(q_{t}, x_{t}\right)}{d_{0}^{t}\left(q_{s}, x_{s}\right)} \sqrt{\frac{d_{0}^{s}\left(q_{t}, x_{t}\right)}{d_{0}^{s}\left(q_{s}, x_{s}\right)} \frac{d_{0}^{t}\left(q_{t}, x_{t}\right)}{d_{0}^{t}\left(q_{s}, x_{s}\right)}}
\end{aligned}
$$

formulas (1) and (2) of the d0s (qt, xt) on behalf of the T technology period as a reference output distance function in the S period.; d0s (qs, xs) represents in present technology period as the reference output distance function in the $S$ period; d0s (qs, xs) on behalf of the S period technology as a reference output distance function in the T period; $\mathrm{d} 0 \mathrm{t}(\mathrm{qt}, \mathrm{xt})$ on behalf of in present technology period as the reference output of technology distance function in the T period .If M0 $(\mathrm{qs}, \mathrm{xs} ; \mathrm{qt}, \mathrm{xt})>1$, Indicates that from $\mathrm{S}$ period to the $\mathrm{T}$ period, TFP for positive growth; If M0 (qs, xs; qt, xt) $=1$, it is TFP zero growth. Similarly, if M0 (qs, xs; qt, xt) $<1$, then illustrate that: TFP for negative growth. In mode (2) $\sqrt{\frac{d_{0}^{s}\left(q_{t}, x_{t}\right)}{d_{0}^{t}\left(q_{t}, x_{t}\right)} \frac{d_{0}^{s}\left(q_{s}, x_{s}\right)}{d_{0}^{t}\left(q_{s}, x_{s}\right)}}$ the efficiency of the change, named two period of technical change, namely Tch. Then we can be obtained:

$$
M_{0}\left(q_{s}, x_{s} ; q_{t} x_{t}\right)=E c h \times T c h .
$$

\section{2) Malmquist Productivity Index}

Fare (1989) and others set up Malmquist productivity index for measuring TFP change in 1994, after they put Malmquist thought into the production analysis. In 1989 Fare defined Malmquist productivity index as:

$$
T F P=\left[\frac{d^{t}\left(x_{t+1}, y_{t+1}\right)}{d^{t}\left(x_{t}, y_{t}\right)} \times \frac{d^{t+1}\left(x_{t+1}, y_{t+1}\right)}{d^{t+1}\left(x_{t}, y_{t}\right)}\right]^{\frac{1}{2}}
$$

In this equation, $d^{t}\left(x_{t+1}, y_{t+1}\right)$ representative of $\mathrm{t}+1$ period technical efficiency level for the performance of the technology at the $\mathrm{t}$ period. $d^{t}\left(x_{t}, y_{t}\right)$ representative of current technical efficiency level for the performance of the technology at the $\mathrm{t}$ period. $d^{t+1}\left(x_{t+1}, y_{t+1}\right)$ representative of current technical efficiency level for the performance of the $\mathrm{t}$ +1 period. $d^{t+1}\left(x_{t}, y_{t}\right)$ representative of $\mathrm{t}$ period technical efficiency level for the performance of the $t+1$ period. When TFP-ch $>1$ represents the technical efficiency up; otherwise, the decline. Since then in 1994 Fare, Grosskopf, Norris and Zhang give a further analysis of total factor productivity change, defined as a technology changes (Tch) multiply by efficiency changes (Ech); that is:

$$
\mathrm{TFP}=\mathrm{Tch} \times \mathrm{Ech}
$$

In the above three type, when Tch $>1$ representative technology progress, production boundary ascend; When Tch $<1$ is for the technical recession, reduce production boundary; When Ech > 1, means technology efficiency up; Otherwise, for efficiency descend. In type (3), the four parts of the value can be work out by linear programming method, and eventually seek total factor productivity, the technology, the technical efficiency of the three changes.

\section{B. Data Collection and Processing}

According to DEA model analysis method, the research object Including 32 provincial-level regions in this paper (Contains province, municipality directly under the central government, autonomous region. except Hong Kong, Macao and Taiwan), and it be divided into four regions: eastern, central and western, northeast, It was formed measured unit in the DEA model. The research subjects include the all national administrative districts, the samples were enough to represent China productivity general features of development. Due to some areas in China system establish was late (such as: Chongqing, etc), accessible data is shorter, we choose 
data for 1985 to 2008. Productivity analysis of data generally include GDP as output, capital and labors as input, this paper using GDP as output data of each province (1978 constant prices), and each province's employment as the input of labor, the stock of fixed capital as the input capital. To estimate the capital stock, generally Economists use the perpetual inventory method (PIM), namely $\mathrm{Kt}=\mathrm{Kt}-1 \times \Phi+\Delta \mathrm{Kt}$ (among them, $\Phi$ for capital years allowance for depreciation. In this paper, we refer to the measure method of Wang Xiaolu et al. [12], from the beginning of year $5 \%$ to $8 \%$ gradually smoothing from 1985 to 2009). Considering the capital increment lag, this paper uses modified model $\mathrm{Kt}=$
$(\mathrm{Kt}-1+\Delta \mathrm{Kt}-1) \times \Phi$. The data of initial capital stock In 1978 was used estimated by Huang Zongyuan and Gong Rukai in 2010(The original data are comes from New China 60 Years of Assembler Statistical Data), using of output-oriented mode, giving a total factor productivity analysis from 1985 to 2008 data of Chinese provinces. We divided total factor productivity into efficiency changes and technology change two breakdown, and further divided the efficiency changes into pure technical efficiency and scale efficiency changes (relative to frontier production surface which scale pay variable). Details can be found in "Table. I" and "Table II".

TABLE I. MaLmquist IndeX ANd DeComposition of Provinces in China ( 1985 To 2008)

\begin{tabular}{|c|c|c|c|c|c|}
\hline & Technology changes & Efficiency changes & Pure-technical efficiency & Scale efficiency & Total factor productivity \\
\hline Beijing & 1.006 & 1.005 & 1.005 & 1.000 & 1.011 \\
\hline Tianjin & 1.001 & 1.007 & 1.017 & 0.991 & 1.008 \\
\hline Hebei & 1.009 & 1.020 & 1.020 & 1.000 & 1.029 \\
\hline Shanghai & 1.032 & 1.000 & 1.000 & 1.000 & 1.032 \\
\hline Jiangsu & 1.023 & 0.999 & 1.000 & 0.999 & 1.021 \\
\hline Zhejiang & 1.025 & 0.991 & 0.991 & 1.000 & 1.016 \\
\hline Fujian & 1.013 & 0.997 & 0.997 & 1.000 & 1.010 \\
\hline Shandong & 1.008 & 1.007 & 0.999 & 1.008 & 1.015 \\
\hline Guangdong & 1.026 & 1.004 & 1.004 & 1.000 & 1.030 \\
\hline Hainan & 1.022 & 0.986 & 0.99 & 0.996 & 1.008 \\
\hline Eastern Average data & 1.0165 & 1.0016 & 1.0023 & 0.9994 & 1.0180 \\
\hline Shanxi & 1.010 & 1.009 & 1.010 & 0.999 & 1.019 \\
\hline Anhui & 0.988 & 0.985 & 0.987 & 0.998 & 0.973 \\
\hline Jiangxi & 1.000 & 1.004 & 1.004 & 0.999 & 1.004 \\
\hline Henan & 0.999 & 1.007 & 1.006 & 1.000 & 1.006 \\
\hline Hubei & 1.008 & 0.992 & 0.993 & 0.999 & 1.000 \\
\hline Hunan & 0.994 & 0.994 & 0.996 & 0.998 & 0.988 \\
\hline Central Average data & 0.9998 & 0.9985 & 0.9993 & 0.9988 & 0.9983 \\
\hline Inner Mongolia & 1.017 & 1.008 & 1.008 & 1.001 & 1.025 \\
\hline Guangxi & 0.993 & 0.997 & 0.998 & 0.999 & 0.991 \\
\hline Chongqing & 1.006 & 1.009 & 1.010 & 0.999 & 1.015 \\
\hline Sichuan & 1.006 & 0.993 & 0.994 & 0.999 & 0.999 \\
\hline Guizhou & 0.989 & 0.999 & 1.003 & 0.996 & 0.988 \\
\hline Yunnan & 0.994 & 1.013 & 1.015 & 0.999 & 1.007 \\
\hline Tibet & 1.010 & 0.994 & 1.000 & 0.994 & 1.004 \\
\hline Shanxi & 1.007 & 1.010 & 1.010 & 1.000 & 1.017 \\
\hline Gansu & 1.005 & 1.011 & 1.015 & 0.996 & 1.016 \\
\hline Qinghai & 1.006 & 1.015 & 1.006 & 1.009 & 1.020 \\
\hline Ningxia & 1.011 & 1.012 & 1.007 & 1.004 & 1.023 \\
\hline Xinjiang & 1.024 & 1.010 & 1.011 & 0.998 & 1.034 \\
\hline Western Average data & 1.0057 & 1.0059 & 1.0064 & 0.9995 & 1.0116 \\
\hline Heilongjiang & 1.014 & 1.002 & 1.004 & 0.998 & 1.016 \\
\hline Jilin & 1.014 & 1.004 & 1.005 & 0.999 & 1.017 \\
\hline Liaoning & 1.018 & 0.998 & 0.999 & 0.999 & 1.017 \\
\hline Northeastern Average data & 1.0153 & 1.0013 & 1.0027 & 0.9987 & 1.0167 \\
\hline The national Average data & 1.009 & 1.003 & 1.003 & 0.999 & 1.012 \\
\hline
\end{tabular}


TABLE II. CHINA MALMQUIST INDEX AND ITS COMPONENTS

\begin{tabular}{|l|l|l|l|l|l|}
\hline & Technology Changes & \multicolumn{1}{|c|}{ Efficiency Changes } & Pure Technical Efficiency & Scale Efficiency & Total Factor Productivity \\
\hline $1985-1990$ & 0.936 & 1.032 & 1.024 & 1.007 & 0.966 \\
\hline $1990-1995$ & 1.058 & 0.970 & 0.981 & 0.989 & 1.026 \\
\hline $1995-2000$ & 1.002 & 1.016 & 1.009 & 1.007 & 1.018 \\
\hline $2000-2005$ & 1.045 & 0.992 & 0.997 & 0.995 & 1.037 \\
\hline $2005-2008$ & 1.007 & 1.006 & 1.009 & 0.997 & 1.013 \\
\hline $1985-2008$ & 1.009 & 1.003 & 1.003 & 0.999 & 1.012 \\
\hline
\end{tabular}

\section{EMPIRICAL ANALYSIS}

Since from the reform and opening up policy, although china's total-factor productivity growth rate is not high, the general trend is fluctuation ascending. This shows that China's economic growth mode transformation is gradually advancing. The progress of the productivity in China was influenced by our reform process and content, with the deepening of the opening, China's productivity change has been more and more influenced by international economic environment change deeply. From the influence factors of the productivity progress, the efficiency improvement less effect. From 1985-2008 China TFP overall change point of view, the national annual average growth $1.2 \%$. This shows that our state's economic growth had preliminary get rid of the pure rely on high extensive style, beginning to rely on rapid TFP growth promoting to the new period. Judging from the factors affecting the TFP decomposition, the technological progress is the main driving force to promote TFP growth. The whole period with an average annual growth rate reached $0.9 \%$, the contribution of the productivity enhancements 75\%,excepted 1985-1990 the technological progress is negative growth, the rest are all positive growth, and the trend of the TFP change basically the same. Efficiency changes annual average growth rate of $0.3 \%$, account for only $25 \%$ of the increase in productivity. Pure technical efficiency changes with an annual average growth rate $0.3 \%$, accounting for $100 \%$ of the variation in the efficiency, the smallest scale efficiency changes, close to 1.0, slightly microscopic recession, and it has smallest impact on TFP change.

From regional perspective, the district difference is bigger. The progress of productivity is very imbalanced and the promotion factors of the productivity progress are also different. Among them, the eastern region is the highest, about the average annual growth of $1.8 \%$. The lowest is in central region, felling by $0.17 \%$ annual. The northeast region and western China is in the medium level, and all maintained a positive growth. Among them, the northeast area keeps an average annual growth of $1.67 \%$, second only to the east; the west keeps an average annual growth of $1.16 \%$, according to the third. This also means that except the central region is characterized by the typical economic growth which is promoted by factors inputs, in other area the productivity promotion has become the main driving force of economic growth. In aspects of productivity growth factors, technological progress is undoubtedly the dominant promotion factors of productivity gains. In eastern coastal areas and the North-East of China ,the technology progress is very outstanding, with an average annual growth rate of $1.65 \%$ and $1.53 \%$, accounting for more than $90 \%$ of the increase in their productivity; Technical progress in the western region is of small contributions, with an average annual growth of $0.57 \%$, less than half of the former area, and the productivity growth only accounts for nearly $50 \%$; The promotion of efficiency accounts for smaller contribution in the productivity improvements. The eastern coastal area and the northeast area grows by $0.16 \%$ and $0.13 \%$ average annual, less than the $10 \%$ of the increase in productivity. Efficiency factors in the western region are of a significant contribution, accounting for more than $50 \%$ of the increase in their productivity. In the changes of efficiency, pure technical efficiency contributed more than $100 \%$ growth, but the scale efficiency declined year by year.

Comparisons from the provinces, productivity progress is more obvious, step by step transformation of economic growth, but the overall growth of total factor productivity is not high, and the economic growth mode transformation is extremely uneven. Most of provinces (except Anhui, Hunan, Guangxi, Sichuan and Guizhou) show that TFP is growing. Among them, there are three provinces at TFP growth rate of $3.0 \%$ and above: Xinjiang (west) , Shanghai (east) , Guangdong ( East), accounting for nearly $1 / 10$;six provinces of TFP growth rate is from $2 \%$ to $3.0 \%$ : Hebei (2.9 \%, East), Jiangsu (2.1\%, Eastern ), Mongolia (2.5\%, west), Qinghai $(2.0 \%$, west), Ningxia $(2.3 \%$, West ), accounting for nearly $1 / 6$. The TFP growth rate of 10 provinces is from 1.0 to $1.9 \%$, accounting for nearly $1 / 3$. i.e East of provinces: Beijing, Zhejiang, Fujian and Shandong, western: Chongqing, Shaanxi and Gansu, three provinces of northeastern are at 1.65 percent, the central only Shanxi province. The other five provinces of TFP is declining, accounting for nearly $1 / 6$. Among them, Anhui of TFP falls by $2.7 \%$, the worst province, Hunan decreases by $1.2 \%$, Guizhou falls by $1.2 \%$, Guangxi downs $0.9 \%$, and Sichuan drops $0.1 \%$. Fluctuations in the data from the provinces to see, the volatility of productivity living in $-2.7 \%$ to $3.4 \%$, and the most volatile; technological progress fluctuations is between $-1.2 \%$ to $3.2 \%$, the second; efficiency change is from $-1.5 \%$ to $2.0 \%$, living in the third ; scope of the changes in pure technical efficiency is from $-1.3 \%$ to $2.0 \%$, and the fourth ; scale living in the efficiency of trading range is between $-0.9 \%$ to $0.9 \%$, minimum . From the point of view in the factors affecting changes in productivity, 
technological progress is at the top place, in which, there are 25 provinces have made technological progress, accounting for $78.1 \%$; Secondly, the pure technical efficiency follows.. Efficiency of 19 provinces and autonomous regions, accounting for $59.4 \%$, of which pure technical efficiency of 19 provinces and autonomous regions, accounting for $59.4 \%$, the scale efficiency only four provinces, only $12.5 \%$. Therefore, the main factors affecting changes in the efficiency is pure technical efficiency change, and scale efficiency change is small, and most of the decline, and the impact is negative and the smallest.

Overall, China's total factor productivity growth increases by period, and China's economic growth has begun to shift from production of inputs -driven productivity gains driven, but the transformation of economic growth is not balanced. Among them, the eastern and northeastern region are as a whole faster pace of technological progress, and efficiency grows significantly, and increasing total factor productivity has become the main driver of economic growth ; in the western region to improve the efficiency is of the most significant, but technical progress is slow, slightly lower total factor productivity growth at the national level, and this is indicating the transformation of economic growth in western regions and the national basic synchronization; transformation of the central region lags far behind economic growth, technological progress, stagnation and inefficiency have become two main factors to restrict the economic growth mode transformation. To enhance national power in terms of productivity, technological progress has become a way of promoting the transformation of China's economic growth in the active force Efficiency grows slowly, especially the scale has become a constraint on economic growth mode transformation of the bottlenecks.

\section{CONCLUSIONS AND RECOMMENDATIONS}

Since 1990 , China total factor productivity improved by period, to achieve rapid growth, and total factor productivity gains to promote China's economic growth has become an important factor in China's economic growth, and the transformation of economic growth mode is steadily advancing.

Technological advances to improve total factor productivity has become a major factor and the first driving force for promoting economic growth mode transformation, especially the efficiency improvements in pure technical efficiency has also become the important factors to promote the economic growth mode transformation.

Transformation of economic growth is not balanced, and there are some differences in the dynamic factors of promoting economic growth mode transformation. Among them, total factor productivity growth is strong in the east coast and northeast. Technological progress has become an absolute increase of total factor productivity in the main, and efficiency improvements are very significant, in terms of economic growth mode transformation in the nation. The level of TFP growth in the western region is close to the national level, the larger internal differences, and technological progress is slow, but the highest efficiency, boost productivity and progress have become the first power. The central region becomes the only negative TFP growth in the region, not only technological stagnation , and suffering a severe decline, as the biggest drag of China's economic growth mode transformation.

China's TFP growth rate has been significantly influenced by the reform process and the profound impact of the changing international environment, growth fluctuations.

Technical progress and efficiency are of each significant compression, both the growth rate one after another, in a period of rapid technological progress, efficiency slow, fast and vice versa.

Scale of decline in efficiency has become a major bottleneck constraining factor to enhance productivity. Since 1990 , our efficiency is not obvious, the size of the efficiency of China's nearly 8 years continued to decline, especially in the backward provinces, down more prominent, and efficiency has become the main factors to hinder progress and TFP growth. Therefore, to promote China's economic growth mode transformation, we must do a good job in the following areas:

\section{A. Continued investments in technology, to promote scientific and technological system, the driving force to strengthen the role of technological progress.}

We should make full use of our complete scientific and technological system, the advantages of investment in science and technology, human resources, science and technology team in the world of comparative advantage and increase intellectual property protection and technological innovation to support efforts to large-scale, high strength to promote scientific progress and technological innovation, and also use scientific and technological progress and innovation to promote economic restructuring and industrial upgrading, promoting the development mode transformation.

\section{B. We should make more policy to support for regional development in central and western area.}

The Technical constraints have become stagnant of the Midwest, especially in economic growth mode transformation in the central provinces. We must continue developing the western region, based on the increase of central China's policy support, to reverse the central technical progress stagnation, and decline in efficiency and gradually narrow the differences with the advanced regions, as soon as possible to catch up with the national average.

\section{We must make efforts to expand domestic demand and reduce dependence on international markets, to improve the domestic economy to resist risks.}

Domestic income growth, large distribution gap has become a key factor in restricting domestic consumption. Therefore, we must take various measures to ensure that income growth is not lower than the GDP growth rate and curb the momentum distribution of gap and improve the level of consumption; And we need to promote the quality of domestic enterprises, construction integrity, and promote re- 
circulation system and improve the efficiency of distribution of the domestic market and product quality, and also reverse the massive outflow of purchasing power of the trend.

\section{Improve the public service platform, the public services, and the management efficiency.}

Lack of high level and improved public services has been seriously hampered China's economic efficiency. Therefore, we should vigorously transform government functions and innovative service concept, breaking research institutes scattered, isolated, closed structure, integrating social resources to focus on production of modern service industry, and to professional, industrial, into the community-oriented, vigorously developing modern service industry, improve service levels and efficiency.

E. Guide the industry, business inter-provincial division of labor, to promote inter-industry, inter-firm vertical and horizontal integration of the development.

Scale inefficiency has become the biggest bottleneck impeding efficiency. Therefore, we need to break the economic development of the administrative division, to strengthen regional coordination and provincial coordination, to avoid duplication and homogenization of competition, to promote the industry, inter-provincial corporate mergers and acquisitions field, and to promote inter- provincial collaboration to develop in depth the economic division of labor. And we must promote crossregional flow of economic resources, optimize the allocation of resources between regions, and improve the efficiency of resource use and development to enhance the scale of economic growth.

\section{REFERENCES}

[1] Gao ChunLiang. Productivity in Urban Area through 1998-2003: an Empirical Study Based on DEA[J]. Modern Economic Science, Xi'an, PP. 83-88, January, 2007.

[2] Fleisher, B. and Chen, J. the Coastal-Noncostal Income Gap, Productivity, and Regional Economic Policy in China[J]. Journal of Comparative Economics, 1997,(25): 220-236.

[3] Ye Yumin. The Calculation and Analysis of the Total Factor Productivity of the Whole Country and the Provinces[J]. Economist, Chengdu, PP. 115-121, PP. March, 2002.

[4] Guo Qingwang, Zhao Zhiyun and Jia Junxue. Analysis of the Total Factor Productivity of China's Provinces Economy [J]. World Economy, Beijing, PP. 46-53,May,2005.

[5] Zheng Jinghai, Hu Angang, An Empirical Analysis of the Changes of Productivity Growth in China During the Reform Period [J]. Economics, Beijing, PP. 263-296, January, 2005.

[6] Zhang Jun, Shi Shaohua.Total Factor Productivity Change of China's Economy: 1952-1998[J]. World Economic Papers, Shanghai, PP. 1225, February, 2003.

[7] Cowgill, Paul Andrew. Aproductivity and Efficency Anylasis of Postreform China [D]PhD. Dissertation.UNIVERSITY OF GEORGIA, GEORGIA, 2001.

[8] Wang Bing,Yan Pengfei. Technical Efficiency, Technological Progress and Productivity Growth: An Empirical Analysis Based on DEA [J]. Economic Research, Beijing, PP. 55-65, December,2004.

[9] Kim Xiangyu, China Regional Total Factor Productivity and Its Decision Factors: 1996- 2003[J]. Economic Review,Wuhan, PP. 107112 , May, 2007.
[10] Zhang Xiangsun, Gui Binwei. The Analysis of Total Factor Productivity in China: A Review and Application of Malmquist Index Method [J].The Journal of Quantitative \& Technical Economics, Beijing, PP. 111-122, June, 2008.

[11] Coeli, T.J., Rao, D.S.P.,O’Donnell,C.J.,Battese,G.E.. An Introduction to Efficiency and Productivity (2nd,Chinese edition) [M]. Beijing: Renmin University of China Press, PP. 297-298, 2009.

[12] Wang Xiaolu Fan Gang Liu Peng, Transformation and Growth Patten and Growth Sustainability in China $[\mathrm{J}]$. Economic Research, Beijing, PP. 4-16, January, 2009.

[13] Huang Zongyuan, Gong Rukai. Calculation of Physical Stock Capital in China's Provinces: 1978 - 2007 [J]. Journal of Guangxi Normal University, Guilin, PP. 74-80, February, 2010. 